\title{
PEMBENTUKAN PEER EDUCATOR DALAM UPAYA PENINGKATAN KUALITAS REMAJA MELALUI PEMBERIAN AKSES INFORMASI TENTANG PENDEWASAAN USIA PERKAWINAN DI DESA SEMBUNG KECAMATAN NARMADA KABUPATEN LOMBOK BARAT
}

\author{
Nurul Qamariah Rista Andaruni ${ }^{1 *}$, Aulia Amini ${ }^{2}$, Ana Pujianti Harahap ${ }^{3}$, Rizkia Amilia ${ }^{4}$ \\ ${ }^{1 *}$ Prodi Kebidanan, FIK, Universitas Muhammadiyah Mataram \\ 2Prodi Kebidanan, FIK, Universitas Muhammadiyah Mataram \\ ${ }^{3}$ Prodi Kebidanan, FIK, Universitas Muhammadiyah Mataram \\ ${ }^{4}$ Prodi Kebidanan, FIK, Universitas Muhammadiyah Mataram \\ Corresponding author : \\ E-mail : rista.andaruni90@gmail.com
}

Diterima 22 Agustus 2019, Disetujui 04 September 2019

\begin{abstract}
ABSTRAK
Permasalahan yang kami temukan di Desa Sembung yakni terdapat $29 \%$ perkawinan remaja. rata-rata pengetahuan remaja tentang dampak perkawinan muda masih sangat kurang, pelaksanaan perkawinan remaja masih didukung oleh budaya setempat, dan sebagian besar remaja yang telah melakukan perkawinan muda mengalami putus sekolah. Oleh sebab itu, kami membentuk peer educator tiap dusun untuk memudahkan remaja mengakses informasi terkait pendewasaan usia perkawinan. Hasil kegiatan ini sangat berdampak positif baik bagi remaja khususnya maupun orangtua dan masyarakat, terbukti $90 \%$ terjadi peningkatan pengetahuan dan sikap terhadap pendewasan usia perkawinan, sedangkan hasil uji lapangan sebesar $80 \%$ remaja mampu menjadi konselor sebaya (peer educator).
\end{abstract}

Kata kunci: perkawinan remaja, peer educator, pendewsaan usia perkawinan

\section{ABSTRACT}

The problem we found in Sembung Village is that there are $29 \%$ of teenage marriages. The collective knowledge of adolescents about the impact of young unions is still lacking, the implementation of underage marriages supported by local culture, and the majority of adolescents who have committed young marriages experience dropouts. Therefore, we formed peer educators in each hamlet to facilitate youth accessing information related to the age of marriage. The results of this activity are very favorable for both adolescents in particular as well as parents and the community, as evidenced by $90 \%$ increase in knowledge and attitudes towards the demise of marriage age, while field test results by $80 \%$ of adolescents can become peer educators.

Keywords: underage marriages, peer educator, related to the age of marriage

\section{PENDAHULUAN}

Konsensus global tentang perlunya penghapusan perkawinan dini, kawin paksa, dan perkawinan usia anak semakin mengemuka dalam beberapa tahun terakhir. Perkawinan usia anak mengakhiri masa remaja anak perempuan, yang seharusnya menjadi masa bagi perkembangan fisik, emosional dan sosial mereka. Anak perempuan yang telah menikah cenderung memiliki tingkat pendidikan yang lebih rendah. Hal ini disebabkan perkawinan dan pendidikan dianggap bertentangan ketika anak perempuan yang menikah menghadapi keterbatasan mobilitas, kehamilan dan tanggung jawab terhadap perawatan anak. Menurut salah satu laporan, 85 persen anak perempuan di Indonesia mengakhiri pendidikan mereka setelah mereka menikah, namun keputusan untuk menikah dan mengakhiri pendidikan juga dapat diakibatkan kurangnya kesempatan kerja. Terdapat sekolah di Indonesia yang menolak anak perempuan yang telah menikah untuk bersekolah. (Simanjuntak H, 2015).

Berdasarkan interview dan wawancara di lapangan, kami menemukan permasalahan yakni (1) Desa tersebut terdapat 29\% perkawinan remaja., (2) Rata-rata pengetahuan remaja tentang dampak perkawinan muda masih sangat kurang, (3) Pelaksanaan perkawinan remaja masih didukung oleh budaya setempat, (4) Sebagian besar remaja yang telah melakukan perkawinan muda mengalami putus sekolah. Salah satu alternatif untuk mengurangi angka perkawinan anak ialah dengan membentuk peer educator tiap dusun, 
sehingga remaja dengan mudah mengakses informasi terkait pendewasaan usia perkawinan dan kesehatan reproduksi remaja.

\section{METODE}

\section{Subjek Kegiatan}

Program pengabdian ini dilaksanakan pada bulan agustus yang berlokasi di Majelis Ta'lim Dusun Sembung Lauk dengan jumlah peserta 25 orang. Metode kegiatan yang digunakan adalah dengan metode pelatihan. Pelaksanaan kedua metode tersebut dilakukan dengan cara: (1) Ceramah, kegiatan ini mengutamakan pemberian materi secara lisan dan tulisan kepada peserta dengan memberikan kesempatan saling berdiskusi dan bertanya terhadap materi yang disampaikan agar terbentuk satu pemahaman antara pemateri dan peserta; (2) Role Play, suatu bentuk adegan yang disusun dalam suatu skenario untuk memberi kesempatan kepada peserta melakukan suatu peran tertentu sehingga memperoleh keterampilan yang akan dicapai. Dalam kegiatan role play peserta ditempatkan pada situasi menjadi konselor dan konseli untuk mendapatkan pengalaman baru dan nyata tentang proses konseling sebaya; (c) Focused Group Discussion (FGD), suatu teknik diskusi kelompok yang digunakan untuk mendapatkan gambaran dari berbagai pendapat atau opini terhadap permasalahan yang dihadapi. Para peserta dibagi dalam 4 kelompok untuk diminta mengemukakan pendapat-pendapatnya pada suatu masalah tertentu secara terarah, dengan memberikan solusi terhadap permasalahan tersebut. Teknik ini menggunakan monopoli genre untuk menentukan kasus apa yang akan didapatkan tiap kelompok. Dalam waktu antara 30 menit peserta diminta mendiskusikan masalah yang sudah dirancang oleh pemateri (trainer), sehingga peserta mempunyai pemahaman baru tentang berbagai masalah dari berbagai sudut pandang yang berbeda dari setiap peserta; (d) Simulasi, hampir sama dengan role play, tetapi peserta memerankan dirinya sendiri menjadi peer educator. Didalam simulasi, setting permainannya adalah situasi nyata yang akan dihadapi peserta sebagai konselo. Seorang peserta diminta memberikan solusi terkait permsalahan yang dihadapi oleh teman sebayanya.

Tahapan Kegiatan

Pra Lapangan

Pada tahap ini, tim melakukan kegiatan yakni:
1. Melakukan koordinasi dengan aparat Desa serta Kader guna melakukan ijin pelaksanaan kegiatan PKMS.

2. Melakukan survey lokasi untuk kegiatan pelatihan, yang dilakukan di Dusun sembung Lauk.

3. Menyiapkan modul pelatihan sebagai pegangan remaja saat pelatihan berlangsung.

\section{Pelaksanaan Kegiatan}

1. Pelatihan hari I dengan menyampaikan materi Kesehatan Reproduksi Remaja, Triad Kesehatan reproduksi remaja dan Peer educator.

2. Pelatihan hari ke-2 dengan menyampaikan materi pendewasaan usia perkawinan, komunikasi konseling dan isu gender.

3. Pelatihan hari ke-3 dengan melakukan praktik menjadi peer educator.

4. Melakukan monitoring dan evaluasi untuk melihat dampak positif dari pelatihan tersebut.

\section{Pasca Kegiatan}

Tim melakukan evaluasi terhadap kemampuan remaja baik dalam pengetahuan maupun sikap terhadap pendewasaan usia perkawinan. Di samping itu, tim juga melakukan evaluasi kepada remaja terhadap cara berkomunikasi dan memberikan konseling atau solusi terhadap kasus yang telah diberikan Tim PKMS.

\section{HASIL DAN PEMBAHASAN}

Kegiatan ini telah dilaksanakan dengan baik sesuai rencana yang telah disiapkan. Kegiatan dimulai dengan (a) Persiapan, Adapun persiapan yang dilakukan meliputi : (1) Melakukan sosialisasi terhadap aparat desa untuk memastikan keberlangsungan kegiatan ini dengan mengungkapkan time schedule dan hal-hal yang menjadi konsekuensi kegiatan tersebut, (2) Melakukan koordinasi dan TOT (training for trainer) tentang pelatihan pembentukan peer educator kepada tim mahasiswa yang akan membantu program pengabdian ini secara berkelanjutan. Tim mempersiapkan 5 mahasiswa untuk menjadi trainer dan pendamping kegiatan konselor sebaya, (3) Mempersiapkan materi pelatihan dan pembuatan modul peer educator yang akan diberikan kepada seluruh peserta. (b) Pelaksanaan, Dalam tahap pelaksanaan kegiatan PKMS ini sesuai dengan rencana pelaksanaan dan kesepakatan dengan aparat desa. Tahapan kegiatan tersebut antara lain : (1) Pembuatan modul peer educator tentang pendewasaan usia perkawinan: Kegiatan ini bertujuan untuk memberikan bekal kepada peserta agar dapat melakukan kegiatan konselor sebaya dengan lebih praktis. Modul ini 
berisikan tentang petunjuk praktis dalam melakukan konselor sebaya disertai dengan gambar praktek konseling dan lampiran contoh proses konseling. Disamping itu modul juga dilengkapi dengan contoh kasus masalah remaja beserta petunjuk cara menyelesaikannya melalui konselor sebaya serta materi yang diberikan saat pelatihan yang membantu remaja dalam memberikan solusi terhadap kasus yang ditemui. Diharapkan modul ini dapat dijadikan referensi bagi pelaksanaan peer educator untuk memudahkan pengembangan kelompok peer educator di Desa Sembung. (2) Pelatihan: Kegiatan berikutnya adalah melakukan pelatihan dasar peer educator. Tujuan dari kegiatan ini adalah : (a) Memperkenalkan program peer educator sebagai alternatif pemecahan masalah (problem solving) bagi para remaja, (b) Memberikan pengetahuan dan pemahaman tentang proses peer educator, (c) Membentuk karakteristik dasar seorang konselor sebaya, (d) Meningkatkan kepekaan terhadap lingkungan sekitar, (e) Meningkatkan kompetensi dan keterampilan peserta dalam kegiatan peer educator, (f) Membentuk karakter remaja (peer educator) yang sesuai dengan kebutuhan program, (g) Menyebarluaskan teknik peer educator sebagai salah satu alternatif pemecahan masalah bagi remaja

Disamping itu kegiatan ini juga untuk menjembatani informasi terbaru berkaitan dengan permasalahan yang dihadapi oleh teman-teman sebayanya dan permasalahan individual saat melakukan kegiatan konseling, sehingga tim PKMS dapat menyusun langkahlangkah baru dan membantu penyelesaian masalah yang dihadapi oleh peserta.

Kegiatan yang dilakukan telah mampu memberikan kontribusi positif terhadap remaja secara individual dan Desa secara kelembagaan. Hal ini dapat dijelaskan sebagai berikut : (1) Pelatihan yang dilakukan telah mampu membuka wawasan baru terhadap fungsi dan peran remaja itu sendiri.. (2) Pelatihan yang diikuti secara individual telah mampu memberikan kontribusi tentang pemahaman diri sendiri dan pengenalan diri yang selama ini kurang dilakukan. Individu yang mengikuti pelatihan mendapatkan kesempatan mengenali dirinya melalui assessment yang dilakukan oleh trainer. Disamping itu pelatihan telah mampu memberikan kesempatan individu memperbaiki karakter (positif) sesuai dengan kompetensi yang dibutuhkan oleh seorang konselor. Karakter tersebut antara lain : mau mendengarkan, empati, suka menolong (tidak egois), proaktif, kreatif dalam menyelesaikan masalah dan kesediaan untuk memikirkan masa depan dengan lebih jelas (Prakoso \& Wahyuni, 2015).

Kompetensi yang dimiliki mampu mencegah timbulnya perilaku negatif lainnya yang dimiliki oleh sebagian remaja. Selain itu timbul kemampuan baru dalam aspek psikososial yang selama ini kurang berkembang yaitu memahami diri dan orang lain serta mau terlibat dalam masalah yang dihadapi orang lain.

\section{SIMPULAN DAN SARAN}

Berdasarkan implementasi kegiatan PKMS dapat disimpulkan bahwa (a) Pelaksanaan kegiatan ini telah mampu meningkatkan pengetahuan dan keterampilan komunikasi remaja dalam memberikan solusi terhadap kasus yang ditemui melalui kegiatan peer educator, (b) Dapat mengantisipasi munculnya perilaku negatif remaja (kenakalan remaja), (c) Dapat meningkatkan rasa empati dan kepedulian remaja terhadap lingkungan dan teman sebayanya.

Hasil kegiatan ini sangat berdampak positif baik bagi remaja khususnya maupun orangtua dan masyarakat pada umumnya, terbukti $90 \%$ terjadi peningkatan pengetahuan dan sikap terhadap pendewasan usia perkawinan, sedangkan hasil uji lapangan sebesar $80 \%$ remaja mampu menjadi konselor sebaya (peer educator).

\section{DAFTAR RUJUKAN}

Child Protection Law no. 23/2002, article 26, 1 (c).

Gage, A.J. (2013). Association of child marriage with suicidal thoughts and attempts among adolescent girls in Ethiopia. Journal of Adolescent Health, 52, (5), p. 654; and Evenhuis and Burn, Just Married, Just a Child, p. 20.

ICRW. (2005). Development Initiative on Supporting Health Adolescents (DISHA) Project: Analysis of quantitative baseline survey data conducted in 2004. Washington, D.C: ICRW and Mathur, Greene and Malhotra. (2003). Too Young to Wed: The lives, rights and health of young married girls. Washington, D.C.: ICRW.

Kim, et al. 2013. When Do Laws Matter? National Minimum-Age-of-Marriage Laws, Child Rights, and Adolescent Fertility, 1989-2007. Law \& Society Review, 47, (3), pp. 589, 591.

Marriage Law no. 1/1974, article 7 (1).

Minchew, Thompson and Kennedy. (2014). The Summer of the Summit - Now what for child, early and forced marriage? Girls Not Brides. Available from: 
http://www.girlsnotbrides.org/summer -summit-now-child-early-forced-

marriage/, Accessed 28 January 2015.

RISTEKDIKTI. (2018). Buku Panduan Pelaksanaan Penelitian dan Pengabdian Kepada Masyarakat Edisi XII Tahun 2018. RISTEKDIKTI. Jakarta

Simanjuntak, H. (2015). Aceh student expelled from school over marriage. Jakarta: The Jakarta Post. Available from: http://www.thejakartapost.com/news/ 2015/01/23/aceh-student- expelledschool-over-marriage.html. Accessed 23 June 2015.

UNICEF. (2012). Progress for Children: A report card on adolescents: Number 10. New York: New York: UNICEF. p. 47.

United Nations General Assembly.(2014). The Road to Dignity by 2030: Ending poverty, transforming all lives and protecting the planet - Synthesis report of the Secretary-General on the post-2015 sustainable development agenda. New York: United Nations A/69/700; and United Nations General Assembly. Resolution Adopted by the General Assembly 69/XX: Child, early and forced marriage. Agenda Item 65(a), Version 14, New York: United Nations.

United Nations Children's Fund. (2014). Ending Child Marriage: Progress and prospects. New York: UNICEF, p. 1.

WHO. (2014). World Health Statistics 2014. Geneva, Switzerland: World Health Organization; Raj, A. (2010). When the mother is a child: The impact of child marriage on the health and human rights of girls. Boston. Archives of disease in childhood. 95, (11), p. 931 